\title{
Flat-Pan Nail-Wide Acquired Epiungual Fibrokeratoma: Report of 4 Cases
}

\author{
André Lencastre ${ }^{a}$ Bertrand Richert ${ }^{b}$ \\ ${ }^{a}$ Department of Dermatology, Hospital de Santo António dos Capuchos, Lisbon, Portugal; ${ }^{b}$ Clinic of Dermatology, \\ Brugmann University Hospital, Brussels, Belgium
}

\section{Established Facts}

- Acquired digital fibrokeratoma (ADFK) is a benign tumor that can appear on the periungual tissue and may cause nail plate deformity ("grooving”).

- Flat epiungual ADFK is one of its less common variants.

\section{Novel Insights}

- Flat-pan nail-wide ADFK expands over the whole width of the nail, only revealed by full reflection of the proximal fold.

- Pressure on the matrix might thus be homogeneous, without any nail grooving.

- Surgery of flat-pan nail-wide epiungual ADFK is straightforward.

\section{Keywords}

Acquired acral fibrokeratoma · Acquired digital fibrokeratoma · Nail tumors · Nail surgery

\begin{abstract}
Acquired digital fibrokeratoma (ADFK) is a benign tumor. Clinically, it usually presents as skin-colored, slow-growing firm fibrous projection with a characteristic hyperkeratotic collarette at its base. It has a predilection for the periungual tissue. Some clinical variations have been described according to its macroscopic appearance and relation to the nail apparatus. The authors present 4 cases of unique ADFK expanding over the whole width of the nail.
\end{abstract}

(c) 2018 S. Karger AG, Basel

\section{KARGER}

(c) 2018 S. Karger AG, Basel

E-Mail karger@karger.com

www.karger.com/sad

\section{Introduction}

Acquired digital fibrokeratoma (ADFK) can appear on the periungual tissue of the digits or toes $[1,2]$. The diagnosis of ADFK is usually made on clinical grounds. Differential diagnosis of ADFK usually includes cutaneous horn, Koenen's tumors, neuroma, or viral warts [1]. We report herein 4 cases of flat epiungual fibrokeratoma, a unique form of ADFK.

\section{Case 1}

A 24-year-old Caucasian woman reported a 7-month history of a flat, pink to skin-colored epiungual nodule on her left great toenail. It showed discrete distal hyperkeratosis and arose directly beneath the proximal nail fold (PNF), spanning the entire width of 

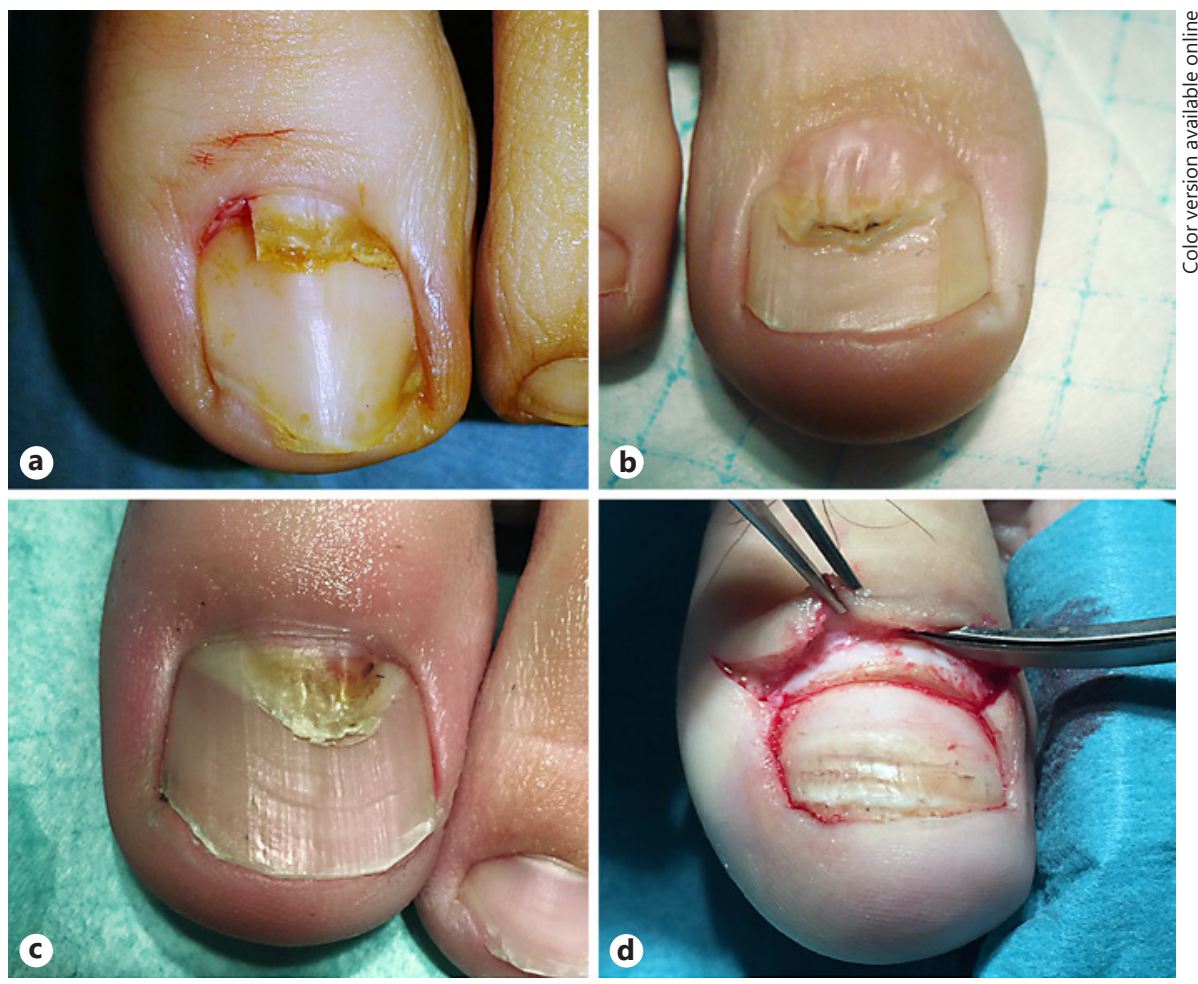

Fig. 1. a From underneath the PNF, a wide ADFK is seen, a medial section of which was removed for histology. b An ADFK with a wide discrete trough on the ventral nail.c A triangle-shaped ADFK with a wide base hidden beneath the PNF. d A wide ADFK only fully visible after reflection of the PNF.

the cuticle above, extending $2 \mathrm{~mm}$ ahead of it. There was no nail plate (NP) deformity. At the patient's request, an incisional biopsy was performed (Fig. 1a). Using a dental spatula, the medial aspect of the nodule was gently dissected from the PNF, above, and NP, below. A fragment of the lesion was collected using a surgical scalpel. The lesion was subsequently conservatively excised. At the 1-year follow-up, neither recurrence nor significant nail dystrophy were noted.

\section{Case 2}

A 17-year-old man presented with a flat, pink nodule, with distal hyperkeratosis that spanned the undersurface of the PNF of the right first toe (Fig. 1b). The NP surface showed a wide discrete trough. Reclining of the PNF revealed that the ADFK originated from the undersurface of the PNF and expanded over the whole width of the plate. Its medial part was thicker than the rest of the lesion. This was divided at its most proximal part. No recurrence or dystrophy was observed 2 years later.

\section{Case 3}

A 13-year-old male adolescent presented with a flat, pink to red, triangle-shaped nodule with a hyperkeratotic tip and a visible base occupying the middle half of the PNF, from under which it arose. During surgery, it was shown to occupy the entire width of the PNF (Fig. 1c).

\section{Case 4}

A 23-year-old male patient presented a clinical case that was similar to the one described in case 1 . However, his lesion was only visible beneath the lateral $2 / 3$ of the PNF, extending just $0.5 \mathrm{~mm}$ ahead of it. During excision, the lesion was revealed to span the entire ventral aspect of the PNF (Fig. 1d).

\section{Methods}

In all cases, the surgical approach was as follows: two oblique lateral incisions were performed on the PNF to allow reflection of the PNF and full exposure of the tumor. Using an elevator, the superior and inferior aspects of the lesion were gently dissected from the PNF above and NP below. Then, the ADFK was severed in a tangential incision at its base. The PNF was laid back into its original position and the oblique incisions sutured. No significant hemorrhage was noted in any case, nor was any type of postsurgical complication observed.

Histopathology of all specimens revealed a polypoid lesion with flat upper and lower surfaces. A slightly acanthotic epidermis, with orthohyperkeratosis towards the anterior edge of the tumor, surrounded a connective tissue core of dense collagen fibers, moderate numbers of mature fibroblasts, small blood vessels, and banal elastic fibers. 


\section{Discussion}

ADFK is most commonly categorized according to its location within the nail unit, for clarity and orientation of the surgical approach [3-5]. Hence, ADFK may be subungual (appearing from underneath the NP, which may be molded by the tumor), intraungual (originating from underneath the NP, dissecting it and appearing as a tumor sandwiched between NP lamellae), epiungual (developing from the undersurface of the PNF, above the NP, often molding its superior aspect forming a sulcum or a groove), or periungual (tumors of the perionychium that, at best, touch the NP, but do not fit the previous descriptions). Also, regarding its clinical aspect, Hwang et al. [6] described 4 types: rod-shaped, dome-shaped, flat and branching [5]. In their series of 20 cases, spanning over 10 years, flat ADFK were found in 4 occasions. The lesions presented with a normal horizontal NP surface without a nail depression.

These 4 cases were striking for three reasons: (1) The distal keratotic tip of the ADFK was barely visible clinically and only full reflection of the PNF revealed the very large size of the tumor, spanning almost the whole width of the plate. (2) As pressure was homogenous on the whole matrix, there was no significant NP dystrophy, as usually seen in other types of epiungual ADFK, except if the ADFK is thicker in its median part (case 2). (3) All these 4 cases arose on a great toenail, in young adults. None recalled previous trauma. A traumatic or infectious origin has been infrequently advocated as a possible cause for ADFK [7-9]. Repeated pressure from the shoe over the PNF may be responsible for the special shape of these ADFK. However, none of the 4 patients wore special footwear in their daily occupation nor practiced any peculiar sport activity.

Surgery showed that in all cases, the tumor originated from the undersurface of the PNF. Its removal was easy and did not expose the surgeon to any intraoperative difficulty. Post-op was uneventful. Neither tumor displayed any specific histopathologic features.

Physicians dealing with nails on a regular basis should be aware of this unusual presentation of ADFK. Collection of further cases may offer clues to the bases of these unusual nail-wide acquired fibrokeratomas.

\section{Statement of Ethics}

The patients provided informed consent for the publication of the case and our study complies with human rights.

\section{Disclosure Statement}

The authors declare no conflicts of interest.

\section{References}

1 Cahn RL: Acquired periungual fibrokeratoma. A rare benign tumor previously described as the garlic-clove fibroma. Arch Dermatol 1977;113:1564-1568.

2 Verallo VV: Acquired digital fibrokeratomas. Br J Dermatol 1968;80:730-736.

3 Lee CY, Lee KY, Kim KH, Kim YH: Total excision of acquired periungual fibrokeratoma using bilateral proximal nail fold oblique incision for preserving nail matrix. Dermatol Surg 2010;36:139-141.
4 Yélamos O, Alegre M, Garcés JR, Puig L: Periungual acral fibrokeratoma: surgical excision using a banner flap. Actas Dermosifiliogr 2013;104:830-832.

5 Haneke E, Richert B, Di Chiacchio N: Surgery of the proximal nail fold. In: Richert B, Di Chiacchio N, Haneke E (eds): Nail Surgery, 1st ed., Informa Healthcare, London 2010, pp 49-50.
6 Hwang S, Kim M, Cho BK, Park HJ: Clinical characteristics of acquired ungual fibrokeratoma. Indian J Dermatol Venereol Leprol 2017;83:337-343.

7 Herman PS, Datnow B: Acquired (digital) fibrokeratomas. Complication of ingrown toenail. Acta Derm Venereol 1974;54:73-75.

8 Sezer E, et al: Acquired periungual fibrokeratoma developing after acute staphylococcal paronychia. Eur J Dermatol 2009;19:636-637.

9 Amarouch H, et al: Un fibrokératome digital acquis post-staphylococcique: une nouvelle observation. Presse Med 2015;44:843-845. 